\title{
Estimating poverty transitions using repeated cross-sections: a three-country validation exercise
}

\author{
Guillermo Cruces • Peter Lanjouw • \\ Leonardo Lucchetti · Elizaveta Perova • \\ Renos Vakis • Mariana Viollaz
}

Received: 18 January 2013 / Accepted: 28 July 2014

(C) Springer Science+Business Media New York 2014

\begin{abstract}
This paper validates a recently proposed method to estimate intra-generational poverty transitions through repeated cross-sectional surveys. The technique allows the creation of a "synthetic panel" - done by predicting future or past household income or consumption using a set of simple modeling and error structure assumptions - and thus permits the estimation of lower and upper bounds of the joint distribution of poverty and non-poverty transitions. We validate the approach in three different settings where good panel data exist (Chile, Nicaragua, and Peru). In doing so, we also carry out a number of refinements to the validation procedure and expand the set of tests undertaken. The results are broadly encouraging in estimating the joint probabilities of poverty and non-poverty transitions between two periods in all three contexts. The approach is also robust to a broad
\end{abstract}

Electronic supplementary material The online version of this article (doi: 10.1007/s10888-014-9284-9) contains supplementary material, which is available to authorized users.

G. Cruces · M. Viollaz

CEDLAS, Departamento de Economía, Facultad de Ciencias Económicas, Universidad Nacional de La Plata, Calle 6 e/47 y 48, 3er. Piso, Oficina 322, (1900) La Plata, Argentina

G. Cruces

e-mail: gcruces@cedlas.org

M. Viollaz

e-mail: mviollaz@cedlas.org

P. Lanjouw · L. Lucchetti - E. Perova $\cdot$ R. Vakis $(\square)$

The World Bank, 1818 H Street NW, Washington, DC 20433, USA

e-mail: rvakis@worldbank.org

P. Lanjouw

e-mail: planjouw@worldbank.org

L. Lucchetti

e-mail: 1lucchetti@worldbank.org

E. Perova

e-mail: eperova@worldbank.org 
set of additional "stress" and sensitivity tests, especially in cases where richer model specifications can be estimated. Finally, we test whether the scope of synthetic panels can be expanded in three new directions, namely comparing between income and consumption welfare measures; the robustness to longer intervals (the approach does especially well in predicting long-term poverty transition patterns); and the robustness to two transition lines instead of one. Overall, the results lend support to the application of this approach to settings where panel data are absent.

Keywords Chile $\cdot$ Poverty dynamics $\cdot$ Poverty transitions $\cdot$ Nicaragua $\cdot$ Peru $\cdot$ Poverty · Pseudo-panels $\cdot$ Synthetic panels

\section{Introduction}

Recent years have seen the study of intra-generational mobility in and out of poverty increasingly capture the attention of policy makers and researchers. The type of policies needed to attack persistent poverty may be quite different from those required to address transient poverty or movements in higher parts of the income distribution. When measuring mobility and poverty dynamics, panel datasets that follow individuals or households over time constitute the most appropriate source of information. Unfortunately, such surveys pose substantial empirical challenges. First, because they are typically costly and complex to administer panel datasets (especially in developing countries) that track individuals or households over time are rare. This is particularly true for longer term panel data (that track the same unit of analysis for more than 5-10 years). Second, and connected to the previous point, it is usually complicated to revisit households who move physically or dropout from panel data surveys. As such, non-random attrition may significantly bias results, leading to an underestimation of the actual mobility in the general population [1]. Finally, classical measurement error will also introduce bias in the mobility estimates.

Because of growing concern to evaluate transitions into and out of poverty, an emerging body of research exists to develop techniques that allow the measuring of poverty transitions in the absence of panel data by using cross-sectional surveys. Most of the literature has focused on what is commonly referred to as a pseudo-panel approach, which tracks cohorts of individuals over several periods of time. Recent developments on pseudopanel analysis include [2] and [1]. However, these studies usually impose significant data demands and structural assumptions in order to yield mobility and poverty dynamics measures out of repeated cross-sectional surveys. For example, more than two cross sections are often needed and specific functional forms have to be assumed for earnings dynamics [3]. Another critique of the approach is that by aggregating average trends for a given group (or cohort) it assumes away key intra-group mobility, which may be equally or more important than aggregate mobility. A recent approach developed by [3] explores movements in and out of poverty by imposing fewer restrictions than earlier literature on pseudopanels. The method produces lower and upper bound estimates of poverty transitions which are expected to sandwich true poverty transition estimates obtained from actual panel datasets.

This paper seeks to validate this "synthetic panel" approach by estimating intragenerational poverty transitions by means of repeated cross-sectional surveys. We focus on Chile, Nicaragua, and Peru; three countries for which we have panel datasets that follow households for more than two rounds. This allows us to compare true estimates of poverty dynamics using the three panel datasets against the estimates obtained by applying the [3] 
synthetic panel approach in which individual rounds of the panels are treated as though they were repeated cross-sectional surveys. ${ }^{1}$

In doing so, the paper makes four contributions to the existing literature. First, we extend the validation by [3] in three different countries and regional context than the original piece, performing a similar range of sensitivity analyses and robustness tests to assess the methodology. We also introduce additional exercises that allow us to further assess whether the technique is sensitive to various alternative specifications and assumptions. For example, we test whether the use of real retrospective asset ownership information ${ }^{2}$ or introducing interactions between time invariant household characteristics and geographical controls and regional fixed effects (suggested by [3], but not applied) help increase predictive power and narrow the bound estimates. We find that in most cases these model enhancements improve the bounds considerably.

Second, we test the robustness of the technique to estimate poverty transitions using consumption and income to define welfare. This is particularly useful, as many surveys around the world will only have one of the two welfare indicators but not both. In addition, given the tendency for income to vary more than consumption and as well as to be more difficult to measure, testing whether the technique works for both welfare measures is important.

Third, we test for robustness to longer intervals and specifically whether the time length between cross sectional data affects the technique's performance. This is a key question for poverty dynamics analysis as it is important to know whether the technique can provide accurate predictions both in the short-term as well as the long-term. As discussed earlier, while short-term panel data are relatively common in developing country settings, they rarely exceed more than three years in length, making any analysis of long term poverty transitions almost impossible. Evaluating the performance of this approach for longer spans of years is therefore crucial. In this paper, we take advantage of our diverse settings and panel data to test the performance of different interval lengths between the two rounds of cross-sectional surveys, from a one-year interval in Peru all the way up to ten years in Chile.

Finally, we extend the validation for the case of two "transition" lines. We do this by exploring the joint distribution of poverty and non-poverty transitions in the presence of two poverty lines, giving rise to a three by three transitional matrix instead of the original two by two. This is especially useful as it allows the study of transitions across multiple parts of the distribution (for example extreme and moderate poverty, or poverty and middle class).

In all, our results indicate that the methodology performs reasonably well in predicting the joint probabilities of poverty/non-poverty by means of two rounds of cross-sectional data; the two bounds overlap or fully encompass the true - poverty dynamic measures in most of the cases studied. In many of the cases where they do not, the bounds fall within the 95 percent confidence interval of the true estimate.

\footnotetext{
${ }^{1}$ The use of "true" poverty dynamics in this paper relates to how close the approach comes to replicate panel data results. It remains that the typical panel data set may itself suffer from measurement error and high attrition rates, resulting in error-prone estimates of poverty transitions.

${ }^{2}$ In this paper, we actually improve on [3] inability to use retrospective information. In their case, in the absence of retrospective information in their data, they force cross-sectional information to be time-invariant and retrospective by making use of the two-year panel structure of the dataset - i.e. they insert the value of variables from the first round into the second round of the panel. By contrast, in this paper we estimate the underlying models of consumption required to implement the methodology using actual retrospective asset ownership and show how this increases the predictive power of the models. We also test whether the results using actual versus retrospective information using the forced approach as in [3] differ.
} 
We also find that the particular specification of the underlying model of income/consumption matters for reducing the bounds, with considerable progress possible following the introduction of interaction terms and retrospective asset ownership variables as regressors. Results are generally stable to a large number of sensitivity analyses and robustness checks. The technique does better in predicting long-term poverty transition patterns and performs similarly whether we use two threshold lines instead of one.

The next section summarizes the technique. Section 3 discusses the data and the approach to ensure comparability of the tests across the three countries. The main results are presented in Section 4. Section 5 discusses a range of robustness checks, while Section 6 presents the results of the new tests we introduce, namely the choice of the welfare measure, panel time span performance and the case of two threshold lines. Section 7 concludes.

\section{Methodology}

This section largely relies on [3]. We assume two rounds of repeated cross-sectional surveys. Calling $y_{i t}$ round $t$ household log per capita consumption or income (where $t=1,2$ ) of household $i$ and $z$ the poverty line, we are interested in estimating the fraction of poor households in the first round of the survey who escaped poverty $\left(\operatorname{Pr}\left(y_{i 2}>z\right.\right.$ and $y_{i 1}<$ $z))$ or remain poor $\left(\operatorname{Pr}\left(y_{i 2}<z\right.\right.$ and $\left.\left.y_{i 1}<z\right)\right)$ in the second round of the survey, and the fraction of non-poor households in the first round of the survey who became poor $\left(\operatorname{Pr}\left(y_{i 2}<\right.\right.$ $z$ and $\left.y_{i 1}>z\right)$ ) or remained non-poor $\left(\operatorname{Pr}\left(y_{i 2}>z\right.\right.$ and $\left.\left.y_{i 1}>z\right)\right)$ in the second round of the survey. Note that the poverty transition measures we are introducing are based on joint probabilities (i.e., the probability that a person is not poor in the first round and falls into poverty in the second round), while the concept of poverty dynamics has also been analyzed as a conditional probability (i.e., the probability that a person falls into poverty in the second round given that he was not poor in the first round).

The estimation of these joint probabilities cannot be performed directly by using repeated cross-sectional surveys, since all households are interviewed only once, either in the first or the second round of the survey. However, we can straightforwardly estimate the relationship between consumption or income and time invariant characteristics in each round:

$$
y_{i t}=\beta_{t}^{\prime} x_{i t}+\varepsilon_{i t}, \quad t=1,2
$$

where $x_{i t}$ is a vector of time-invariant characteristics (or characteristics that can be easily recalled from one round to the other one) of household $i$ in round $t$ of the survey and $\varepsilon_{i t}$ is an error term. Using observations from the second round, we can predict consumption or income in the first round $\left(\hat{y}_{i 1}^{2}\right)$ by means of the same observed vector of time-invariant or retrospective characteristics $\left(x_{i 1}^{2}\right)$ and the first round OLS estimates of parameters $\hat{\beta}_{1}$, where the superscript refers to observations of households surveyed in the second round. Lower and upper bound estimates of poverty transitions are derived from two different sets of assumptions about the correlation between the error term in the first round and in the second round.

Dang et al. [3] argue that the correlation between both error terms is likely to be nonnegative. ${ }^{3}$ If we are willing to assume zero correlation between the first round and the

\footnotetext{
${ }^{3}$ Correlation between error terms will be non-zero in two cases: (i) the error term includes an individual fixed effect and (ii) shocks to consumption persist over time. Dang et al. [3] argue that correlation between error terms will almost certainly be positive if either condition holds. In their study using Vietnamese and Indonesian data they present empirical support in favor of this assumption.
} 
second round error terms, [3] propose to predict consumption or income in the first round by randomly drawing with replacement for each household $i$ in the second round from the empirical distribution of first round estimated residuals (denoted by $\hat{\varepsilon}_{i 1}^{2}$ ) as follows:

$$
\hat{y}_{i 1}^{2 U}=\hat{\beta}_{1}^{\prime} x_{i 1}^{2}+\hat{\varepsilon}_{i 1}^{2} \text {. }
$$

Equation 2 allows us to compute estimates of movements in and out of poverty. For example, the fraction of poor households in the first round who escaped poverty in the second time is given by:

$$
\operatorname{Pr}\left(y_{i 2}^{2}>z \text { and } \hat{y}_{i 1}^{2 U}<z\right) \text {. }
$$

Since we are randomly drawing from the empirical distribution of estimated errors, we need to repeat the procedure $R$ times and take average of Eq. 3 in order to estimate movements in and out of poverty. ${ }^{4}$

In all likelihood, however, the correlation between error terms will be positive. By assuming no correlation, Eq. 3 will provide an upper bound estimate of the transitions in and out of poverty. [3] propose estimating a lower bound on poverty transitions by now assuming a perfect positive correlation between error terms. In this case estimates of residuals from the second round $\left(\hat{\varepsilon}_{i 2}^{2}\right)$ can be directly used to predict consumption or income in the first round as follows

$$
\hat{y}_{i 1}^{2 L}=\hat{\beta}_{1}^{\prime} x_{i 1}^{2}+\hat{\varepsilon}_{i 2}^{2} .
$$

Equation 4 allows us to compute lower bound estimates of movements in and out of poverty. ${ }^{5}$ For example, the fraction of poor households in the first round who escaped poverty in the second time is given by

$$
\operatorname{Pr}\left(y_{i 2}^{2}>z \text { and } \hat{y}_{i 1}^{2 L}<z\right)
$$

Since we are not drawing from the empirical distribution of estimated errors, we do not need to repeat the procedure $R$ times as in the upper bound approach. In fact, this last approach provides a clean under-estimate of true poverty transition since we are using household-specific error terms (from the second round in this example). In other words, because movements in and out of poverty is estimated across two survey rounds in which the same disturbance term applies to both consumption or income measures, the lowerbound measure has been "purged" of classical measurement error and thereby provides a lower-bound estimate of "true" poverty transitions.

\section{Data and harmonizing the approach across countries}

\subsection{Harmonizing the approach across countries and specifications}

In order to validate the technique, we use three panel datasets for Chile, Nicaragua, and Peru. True panel estimates of poverty transitions from each country are compared with those that apply the approach above. The three panel datasets we use are: (i) the 1996, 2001, and 2006 National Socio-Economic Characterization Survey (CASEN in Spanish) panel survey

\footnotetext{
${ }^{4}$ In this paper we use 50 repetitions $(R=50)$.

${ }^{5}$ In this paper, we are specifically concerned in estimating transitions in and out of certain parts of the distribution of income (or consumption). And yet, there are arguably many other poverty dynamics and mobility measures and concepts that one could be interested to study. Future work could focus on further validation and robustness checks of this methodology as it could be applied to those measures.
} 
from Chile; (ii) the 1998, 2001, and 2005 National Household Survey on Living Standards Measurement (EMNV in Spanish) panel survey from Nicaragua; and (iii) the 2008-2009 Peruvian National Household Survey (ENAHO in Spanish) panel surveys in Peru. ${ }^{6}$

Our use of these three sets of surveys offers a number of advantages. First, the years considered in the analysis coincide with a period of sustained income growth and reduction of poverty and inequality in the Latin America region; transitions in and/or out of poverty is expected to be large. Second, having several years of panel datasets allows us to validate the technique for different lengths in time both within and across countries ranging from five to ten years in Chile, from three to eight years in Nicaragua and one year for Peru.

\subsection{Data harmonization across countries and specifications}

In order to better assess the synthetic panel technique as it is applied simultaneously in the three countries and settings we apply a number of data harmonizing protocols. First, to avoid potential bias from using panel data to conduct the tests, we follow [3] in by splitting every panel dataset in every country into two randomly drawn sub-samples and then treating one sub-sample from each round as two repeated cross-sectional surveys. We then use these two repeated cross-sections to estimate poverty transitions by applying the method described in Section 2. These results are then compared with the true panel consisting of the other sub-sample.

Second, we apply the same specifications across countries (to the extent possible based on data availability). Specification 1 is the most restrictive in that it only uses variables that best adhere to the time invariance assumptions: household head age, age squared, gender, years of education, and ethnicity. Specification 2 adds geographical controls and regional fixed effects while the specification 3 adds more flexible interaction terms between the first two specifications. Finally, specification 4 adds retrospective asset ownership information (Peru only).

Third, for each country we predict household consumption or income using time invariant characteristics from round 2 and the returns to those characteristics from round 1 . This yields a synthetic panel that uses the actual welfare measure from round 2 and the simulated one from round 1 . We repeat the procedure in the reverse order as an additional validation exercise.

In addition, we apply household weights to address survey design and explore the use of alternative weighting schemes (no weights or individual weights in the robustness tests). For the upper bound poverty transitions calculation, we apply 50 replications to estimate consumption or income in period 1 (and we also explore a higher number of replications as another check). Finally, we restrict our analysis to households whose head is between 25 and 65 years of age in order to avoid life cycle effects which can invalidate the time invariance assumption.

\section{Main results: poverty transitions}

We start the analysis by first comparing true poverty with estimated poverty rates that arise from applying the method proposed in Section 2. For each country, Table 1 reports true point estimates (and 95 percent confidence intervals), together with lower and upper bound

\footnotetext{
${ }^{6}$ Additional information on each dataset can be found in the Online Appendix (electronic supplementary material).
} 
Table 1 Poverty headcount - repeated cross sections vs. panel data

\begin{tabular}{|c|c|c|c|c|c|c|c|c|c|}
\hline \multirow{2}{*}{$\begin{array}{l}\text { Status in } \\
\text { Year[1] }\end{array}$} & \multicolumn{4}{|c|}{ Lower bound estimates } & \multirow{2}{*}{$\begin{array}{l}\text { Truth } \\
{[5]}\end{array}$} & \multicolumn{4}{|c|}{ Upper bound estimates } \\
\hline & [1] & {$[2]$} & {$[3]$} & [4] & & [4] & {$[3]$} & {$[2]$} & [1] \\
\hline \multicolumn{10}{|c|}{ Panel A: Chile 1996} \\
\hline Poverty Rate & 15.16 & 17.02 & 16.44 & . & $\begin{array}{l}24.22 \\
(21.30,27.15)\end{array}$ & . & 24.12 & 23.32 & 28.36 \\
\hline \multicolumn{10}{|c|}{ Panel B: Nicaragua 2001} \\
\hline Poverty Rate & 40.63 & 39.44 & 40.65 & . & $\begin{array}{l}39.03 \\
(35.37,42.68)\end{array}$ & . & 41.53 & 40.86 & 43.61 \\
\hline \multicolumn{10}{|c|}{ Panel C: Peru 2008} \\
\hline Poverty Rate & 35.74 & 35.10 & 34.77 & 33.84 & $\begin{array}{l}33.54 \\
(31.60,35.48)\end{array}$ & 34.47 & 34.26 & 34.83 & 36.22 \\
\hline Obs. Panel A & 823 & 823 & 823 & . & 823 & . & 823 & 823 & 823 \\
\hline Obs. Panel B & 684 & 684 & 684 & . & 684 & . & 684 & 684 & 684 \\
\hline Obs. Panel C & 2,279 & 2,279 & 2,279 & 2,279 & 2,279 & 2,279 & 2,279 & 2,279 & 2,279 \\
\hline
\end{tabular}

Data source: Chile CASEN 1996 and 2006; Nicaragua EMNV 2001 and 2005; and Peru ENAHO 2008 and 2009.

R-squared is calculated for opposite halves of the total Year [1] sample. Results are constrained to the panel sample of households whose heads are between 25 and 65 years old. Results are weighted using household-level survey-sampling weights. Columns [1] show a simple model with household time invariant characteristics. Columns [2] add sub-national controls from census and region of birth fixed-effects. Columns [3] add interactions between household time invariant characteristics and sub-national controls. Columns [4] add retrospective asset ownership. Results in column [5] show actual panel poverty and 95 percent confidence interval between parentheses. Upper bound estimations are based on 50 repetitions

predictions of poverty rates for the four specifications detailed in Section 3.2. ${ }^{7}$ The model predictions are close the true value, even though we note that the true estimates in a number of cases fall just outside the estimated bounds. Still, the true poverty estimate is not too far from the bounds (for example only 0.10 percentage points for the upper bound and model 3 in Chile). Perhaps more important, the estimated bounds overlap with the 95 percent confidence interval of the true estimate. All the bounds (with the exception of the lower bound in Chile) lie within the true confidence interval. Interesting, for Nicaragua and Peru the width of the bounds is smaller than the true confidence interval (e.g., 0.88 percentage points compared to 7.31 points for Nicaragua, respectively).

In terms of specifications, the results improve significantly when we move from the simple specification (model 1) to the other three that include subnational characteristics (model 2), interaction terms (model 3) and retrospective information (model 4). The bounds narrow considerably when moving to these more complex specifications, suggesting that the inclusion of additional variables improves the predictive power. This is consistent with the $\mathrm{R}^{2}$ for these specifications: as we move from the simplest to the more complex model

\footnotetext{
${ }^{7}$ The models used for the upper and lower bound estimates are presented in the online appendix. We use official poverty lines in each country.
} 
they increase substantially confirming the usefulness of adding explanatory variables to improve predictive power. ${ }^{8}$ Still, the differences in the bound width are very small for these specifications to identify a best performer. For example, in Nicaragua, the bounds width for the specification with subnational variables (model 2) is 1.42 percentage points, while for the specification with interactions 0.88 . The difference in the two is indeed very small (less than 0.54 percentage points). Finally, Chile performs the least well in terms of the size of the bounds, which we interpret it to be explained by the relatively small sample size and lower predictive power $\left(\mathrm{R}^{2}\right)$ when compared to those in the other countries.

We next proceed to estimate the joint distribution of poverty and non-poverty transitions as measured by changes in the proportion of households that move across poverty status. Tables 2, 3, 4 provide estimates of poverty transitions in Chile, Nicaragua, and Peru, respectively. The tables show point estimates and 95 percent confidence intervals of true panel poverty transitions, together with lower and upper bound predictions of poverty transitions for all the specifications explained in Section 3.2. In this case true estimates lie within the estimated bounds in all three countries. For example, the model that includes interaction terms (model 3) suggests that between 11.09 and 21.50 percent of households escape poverty in Chile between the first and the second round of the survey, while the actual panel dataset suggests that actual upward mobility out of poverty is somewhere between 16.87 and 22.29 percent (based on the 95 percent confidence interval). Similarly, true downward mobility into poverty lies between 1.79 and 4.11 percent in Chile (95 percent confidence), while the model with interactions predicts that between 2.25 and 4.98 percent entered poverty between first and second rounds of the survey.

As before, predicted power increases rapidly when moving from the first specification towards the other three where we add more complexity; bounds are also reduced considerably. In contrast with the poverty estimates above, in this case we also find that the specifications that include interaction terms (model 3) and retrospective variables (model 4 for Peru) perform the best. This is true for all three countries. For example, moving from the model with subnational characteristics (model 2) to the one with interactions (model 3) in Nicaragua, the $\mathrm{R}^{2}$ increases from 0.45 to 0.53 , while the bounds width for those that escape poverty is reduced from 9.89 percentage points to 7.13 . The one case in Chile where this is not the case (for those that remain non-poor in both periods), the difference between model 2 and 3 is actually only 0.10 percentage points. These results would indicate that model 3 should be preferred to the other two models.

We also find similar albeit slightly weaker results when comparing the use of retrospective variables (model 4) with the one with interactions (model 3) for the case of Peru. Specifically, model 4 has the highest $\mathrm{R}^{2}$ (0.62 compared to 0.57 for model 3 ), while the bounds are the smallest in two of the four joint distributions (poor, poor and poor, non-poor). For the other two, the width of the bound is smaller for model 3, even though the difference is less than 0.03 percentage points. ${ }^{9}$

\footnotetext{
${ }^{8}$ Note that $\mathrm{R}^{2}$ for the various specifications are reported in Tables 2, 3, 4.

${ }^{9}$ As a general point, we should not expect that the gains in precision are linear with the $\mathrm{R}^{2}$. As [3] note, "while there is no obvious theory to guide the specification of what is essentially a forecasting model, certain diagnostics can be looked for guidance. In general one would want to look well beyond explanatory power (a higher $\mathrm{R}^{2}$ would tend to reduce the variance of the prediction error) to consider also statistical significance of the parameter estimates $\hat{\beta}_{1}$ (in order to reduce model error and the resultant overstatement of mobility) and to pay attention as well to concerns about overfitting." This trade-off between achieving higher explanatory power with statistical significance will therefore result in the differences in the bounds estimates across specifications.
} 
Table 2 Transition matrices - repeated cross sections vs. panel data Chile 1996 and 2006

\begin{tabular}{|c|c|c|c|c|c|c|c|}
\hline \multirow[b]{2}{*}{ Status in 1996, 2006} & \multicolumn{3}{|c|}{ Lower bound estimates } & \multirow{2}{*}{$\begin{array}{l}\text { Truth } \\
{[4]}\end{array}$} & \multicolumn{3}{|c|}{ Upper bound estimates } \\
\hline & {$[1]$} & {$[2]$} & {$[3]$} & & {$[3]$} & {$[2]$} & [1] \\
\hline Poor, Poor & 7.46 & 6.68 & 5.35 & $\begin{array}{l}4.64 \\
(3.19,6.07)\end{array}$ & 2.61 & 2.66 & 3.04 \\
\hline Poor, Non-poor & 7.70 & 10.35 & 11.09 & $\begin{array}{l}19.59 \\
(16.87,22.29)\end{array}$ & 21.50 & 20.66 & 25.32 \\
\hline Non-poor, Poor & 0.13 & 0.92 & 2.25 & $\begin{array}{l}2.96 \\
(1.79,4.11)\end{array}$ & 4.98 & 4.94 & 4.55 \\
\hline Non-poor, Non-poor & 84.71 & 82.06 & 81.31 & $\begin{array}{l}72.82 \\
(69.77,75.85)\end{array}$ & 70.90 & 71.75 & 67.08 \\
\hline R-squared & 0.21 & 0.31 & 0.43 & . & 0.43 & 0.31 & 0.21 \\
\hline Residual Correlation & 0.26 & 0.22 & 0.22 & . & 0.22 & 0.22 & 0.26 \\
\hline Observations & 823 & 823 & 823 & 823 & 823 & 823 & 823 \\
\hline
\end{tabular}

Data source: CASEN, 1996-2006.

R-squared is calculated for opposite halves of the total 1996 sample. Results are constrained to the panel sample of households whose heads are between 25 and 65 years old. Results are weighted using household-level survey-sampling weights. Columns [1] show a simple model with household time invariant characteristics. Columns [2] add sub-national controls and region fixed effects. Columns [3] add interactions between household time invariant characteristics and sub-national controls. Results in column [4] show actual panel mobility. 95 percent confidence interval between parentheses. Upper bound estimations are based on 50 repetitions

As expected, the correlation of disturbance terms between the first and second rounds is always positive. The results also show that, as in the case of [3], this residual correlation declines when moving from the first toward the more complex specifications; presumably because the additional explanatory variables are better able to capture the effect of shocks and fixed effects. For example, the model that includes regional controls and fixed effects reduces the residual correlation from 0.71 to 0.66 in Peru. Correlation is reduced further to 0.64 when we include interaction terms and to 0.57 when we include retrospective variables.

In all, we find these results encouraging, validating the original approach in a different regional setting and countries. The next section conducts robustness checks on the approach.

\section{Robustness checks}

We perform additional empirical exercises to test the robustness of the findings under different assumptions of the underlying models and variables used. This is particularly important to evaluate the performance of the technique to simulate various data availability contexts. We conduct all of the tests below for all three countries and permutations permitted by the data. We nonetheless summarize the findings in some cases for space considerations. The online appendix provides a full set of the results. 
Table 3 Transition matrices - repeated cross sections vs. panel data nicaragua 2001 and 2005

\begin{tabular}{|c|c|c|c|c|c|c|c|}
\hline \multirow[b]{2}{*}{ Status in 2001,2005} & \multicolumn{3}{|c|}{ Lower bound estimates } & \multirow{2}{*}{$\begin{array}{l}\text { Truth } \\
{[4]}\end{array}$} & \multicolumn{3}{|c|}{ Upper bound estimates } \\
\hline & [1] & [2] & [3] & & [3] & [2] & [1] \\
\hline Poor, Poor & 40.63 & 39.44 & 37.34 & $\begin{array}{l}35.68 \\
(32.08,39.26)\end{array}$ & 31.09 & 30.97 & 31.64 \\
\hline Poor, Non-poor & 0.00 & 0.00 & 3.31 & $\begin{array}{l}3.35 \\
(2.00,4.70)\end{array}$ & 10.44 & 9.89 & 11.98 \\
\hline Non-poor, Poor & 21.17 & 22.36 & 24.46 & $\begin{array}{l}26.12 \\
(22.82,29.41)\end{array}$ & 30.71 & 30.83 & 30.16 \\
\hline Non-poor, Non-poor & 38.20 & 38.20 & 34.89 & $\begin{array}{l}34.85 \\
(31.27,38.42)\end{array}$ & 27.76 & 28.31 & 26.22 \\
\hline R-squared & 0.30 & 0.45 & 0.53 & . & 0.53 & 0.45 & 0.30 \\
\hline Residual correlation & 0.58 & 0.53 & 0.52 & . & 0.52 & 0.53 & 0.58 \\
\hline Observations & 684 & 684 & 684 & 684 & 684 & 684 & 684 \\
\hline
\end{tabular}

Data source: EMNV, 2001-2005.

R-squared is calculated for opposite halves of the total 2001 sample. Results are constrained to the panel sample of households whose heads are between 25 and 65 years old. Results are weighted using household-level survey-sampling weights. Columns [1] show a simple model with household time invariant characteristics. Columns [2] add sub-national controls from census and region fixed effects. Columns [3] add interactions between household time invariant characteristics and sub-national controls. Results in column [4] show actual panel mobility. 95 percent confidence interval between parentheses. Upper bound estimations are based on 50 repetitions

\subsection{Retrospective information}

Model 4 of Table 4 presents estimates of poverty transitions in Peru based on underlying models of consumption that include retrospective asset ownership as regressors (derived from questions in the cross sectional data on length of ownership of specific assets). To test how well our "constructed" retrospective variables are, we force variables to be retrospective (i.e., by inserting the panel survey value of variables from the first round into the second round) and compare them with those in Table 4. Panel A of Table 5 shows these results. Once again, the methodology is robust to the use of actual data; upper and lower bound estimates sandwich true poverty transitions and its confidence interval, and results are similar to those in Table 4. Interestingly, the bounds' width is further reduced using the actual retrospective (by up to percentage point in two of the four cases). These results suggest that constructing retrospective variables should be pursuit whenever they are available in surveys, even though improvements in their accuracy can be further explored. ${ }^{10}$

\subsection{Place of residence}

Column three of Table 4 shows estimates of poverty transitions in Peru based on a consumption model that includes department of birth as regressor as well as their

\footnotetext{
${ }^{10} \mathrm{We}$ also do a simple test of significance between the 6 asset variables we use in the analysis to study whether the panel values from the first round are not statistically different from those constructed using the information in round two. We find no significant difference for 5 out of the 6 variables.
} 
Table 4 Transition matrices - repeated cross sections vs. panel data Peru 2008 and 2009

\begin{tabular}{|c|c|c|c|c|c|c|c|c|c|}
\hline \multirow[b]{2}{*}{ Status in 2008,2009} & \multicolumn{4}{|c|}{ Lower bound estimates } & \multirow{2}{*}{$\begin{array}{l}\text { Truth } \\
\text { [5] }\end{array}$} & \multicolumn{4}{|c|}{ Upper bound estimates } \\
\hline & [1] & [2] & [3] & [4] & & [4] & [3] & [2] & [1] \\
\hline Poor, Poor & 33.54 & 30.81 & 28.88 & 28.83 & $\begin{array}{l}23.57 \\
(21.83,25.31)\end{array}$ & 18.28 & 17.24 & 17.21 & 15.87 \\
\hline Non-poor & 2.19 & 4.29 & 5.89 & 5.01 & $\begin{array}{l}9.96 \\
(8.73,11.19)\end{array}$ & 16.19 & 17.02 & 17.62 & 20.34 \\
\hline Non-poor, Poor & 0.03 & 2.77 & 4.69 & 4.74 & $\begin{array}{l}10.00 \\
(8.77,11.23)\end{array}$ & 15.29 & 16.34 & 16.37 & 17.70 \\
\hline Non-poor, Non-poor & 64.23 & 62.13 & 60.54 & 61.41 & $\begin{array}{l}56.46 \\
(54.42,58.49)\end{array}$ & 50.24 & 49.40 & 48.80 & 46.08 \\
\hline R-squared & 0.41 & 0.53 & 0.57 & 0.62 & . & 0.62 & 0.57 & 0.53 & 0.41 \\
\hline Residual Correlation & 0.71 & 0.66 & 0.64 & 0.57 & . & 0.57 & 0.64 & 0.66 & 0.71 \\
\hline Observations & 2,279 & 2,279 & 2,279 & 2,279 & 2,279 & 2,279 & 2,279 & 2,279 & 2,279 \\
\hline
\end{tabular}

Data source: INEI - Peruvian National Household Survey (ENAHO), 2008-2009.

R-squared is calculated for opposite halves of the total 2008 sample. Results are constrained to the panel sample of households whose heads are between 25 and 65 years old. Results are weighted using household-level survey-sampling weights. Columns [1] show a simple model with household time invariant characteristics. Columns [2] add sub-national controls from census and region of birth fixed-effects. Columns [3] add interactions between household time invariant characteristics and sub-national controls. Columns [4] add retrospective variables (asset ownership). Results in column [5] show actual panel mobility. 95 percent confidence interval between parentheses. Upper bound estimations are based on 50 repetitions

interactions with household time invariant characteristics. Arguably, department of birth is of great value since it is time-invariant by definition, a necessary requirement for the method to work properly. Panel B of Table 5 tests the robustness of results by replacing department of birth fixed effects by current place of residence fixed effects. Results show that the methodology works well when using current place of residence instead of retrospective data on place of birth. For example, the 95 percent confidence interval of poverty transitions using the true panel lies within the upper and lower bound estimates. The results are also similar to those in Table 4. Finally, the bounds' width is also similar.

\subsection{Sub-national controls: census vs. household survey}

Finally, column three of Table 4 presents estimates of poverty transitions in Peru based on underlying models of consumption that include sub-national controls from the 2005 census at the village-level (i.e., percentage of female head of households, percentage of head of households with primary education incomplete, percentage of head of households with secondary education incomplete, percentage of head of households with secondary education complete, percentage of households with electricity, and percentage of households with access to water), as well as their interaction with household time invariant characteristics. As in the case of department of birth, sub-national controls are of great value since they are time invariant. Panel $\mathrm{C}$ of Table 5 tests the robustness of the results by replacing census information aggregated at the village-level with aggregation at the department 
Table 5 Transition matrices - repeated cross sections vs. panel data using alternative specifications Peru 2008 and 2009

\begin{tabular}{|c|c|c|c|}
\hline Status in 2008, 2009 & $\begin{array}{l}\text { Lower bound estimates } \\
\text { [1] }\end{array}$ & $\begin{array}{l}\text { Truth } \\
\text { [2] }\end{array}$ & $\begin{array}{l}\text { Upper bound estimates } \\
\text { [3] }\end{array}$ \\
\hline \multicolumn{4}{|c|}{ Panel A: using actual instead of retrospective data } \\
\hline Poor, Poor & 28.86 & $(21.83,25.31)$ & 18.36 \\
\hline Poor, Non-poor & 6.82 & $(8.73,11.19)$ & 16.38 \\
\hline Non-poor, Poor & 4.71 & $(8.77,11.23)$ & 15.22 \\
\hline Non-poor, Non-poor & 59.61 & $(54.42,58.49)$ & 50.05 \\
\hline \multicolumn{4}{|c|}{ Panel B: using actual department of residence instead of department of birth } \\
\hline Poor, Poor & 29.76 & $(21.83,25.31)$ & 17.40 \\
\hline Poor, Non-poor & 4.96 & $(8.73,11.19)$ & 16.02 \\
\hline Non-poor, Poor & 3.81 & $(8.77,11.23)$ & 16.17 \\
\hline Non-poor, Non-poor & 61.46 & $(54.42,58.49)$ & 50.40 \\
\hline \multicolumn{4}{|c|}{ Panel C: using sub-national controls from census at the departmental-level } \\
\hline Poor, Poor & 28.66 & $(21.83,25.31)$ & 16.80 \\
\hline Poor, Non-poor & 5.45 & $(8.73,11.19)$ & 16.98 \\
\hline Non-poor, Poor & 4.91 & $(8.77,11.23)$ & 16.78 \\
\hline Non-poor, Non-poor & 60.98 & $(54.42,58.49)$ & 49.44 \\
\hline Observations & 2,279 & 2,279 & 2,279 \\
\hline
\end{tabular}

Data source: INEI - peruvian national household survey (ENAHO), 2008-2009.

$\mathrm{R}$-squared is calculated for opposite halves of the total 2008 sample. Results are constrained to the panel sample of households whose heads are between 25 and 65 years old. Results are weighted using household-level survey-sampling weights. Results in columns [1] are based on a model with household time invariant characteristics, sub-national controls from census, and interactions between household time invariant characteristics and sub-national controls. Panel A adds asset ownership. Results in panel C are based on sub-national controls from census at the departmental-level (instead of at the village-level). Results in column [2] show actual panel mobility. 95 percent confidence interval between parentheses. Upper bound estimations are based on 50 repetitions

level. Predictions are based on the third specification explained in Section 3.2. The results are similar across the three variations. When using census variables at the department-level, the 95 percent true panel confidence interval of poverty transitions lies within upper and lower bound estimates and the width of the bounds is similar to those at the village level. Results are also robust to the use of department-level controls from the survey instead of the census (not shown). Taken together, these results suggest that we can directly use survey information to construct sub-national controls and interaction terms to increase precision of estimates.

\subsection{Sensitivity analysis using different poverty lines}

All previous estimations were computed using the official poverty lines of each country. Figure 1 shows true point estimates, as well as lower and upper bound estimates, for differ- 

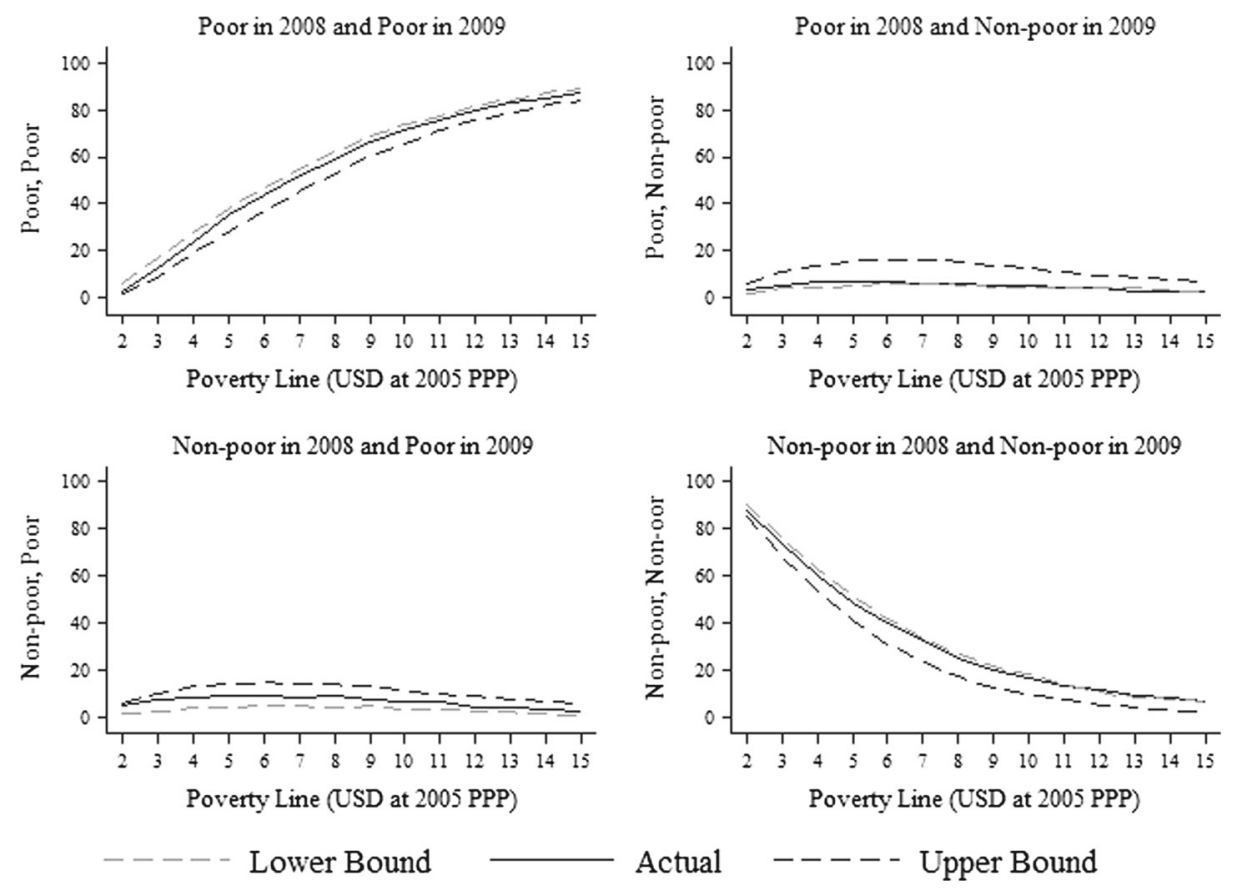

Fig. 1 Poverty dynamics - repeated cross sections vs. panel data for alternative poverty lines Peru 2008 and 2009. Data source: INEI - Peruvian National Household Survey (ENAHO), 2008-2009. Note: Results are constrained to the panel sample of households whose heads are between 25 and 65 years old. Results are weighted using household-level survey-sampling weights. Upper bound estimations are based on 50 repetitions

ent poverty lines in Peru (ranging from \$2 to \$15 USD at 2005 PPP a day). ${ }^{11}$ In general, true panel estimates fall within bounds in all three countries (see online appendix for Chile and Nicaragua). This suggests that the technique is amenable to exploring transitions at various parts of the distribution (see Section 6.3). However, it is not clear whether lower or upper bound estimates perform better in terms of low or high values of poverty lines.

\subsection{Sub-group poverty transitions}

One relevant question in this work is whether the analysis performs well in predicting poverty transitions for specific sub-groups, for example urban and rural areas separately. To explore this further, we estimate joint distributions of poverty transitions for a number of sub-groups: region of residence; gender and education of the household head; urban/rural sector; occupation; sector of occupation; household ownership; access to water and electricity; and ethnicity. Figure 2 compares lower and upper bound estimates with true panel point estimates for different population sub-groups in Nicaragua (see online appendix for Chile and Peru). Predictions are based on the third specification from Section 3.2 and use parameter estimates obtained using the whole sample. The technique performs well for almost all

\footnotetext{
${ }^{11}$ These robustness checks use predictions that are based on the third specification explained in Section 3.2. Results for Chile and Nicaragua can be found in the online appendix.
} 

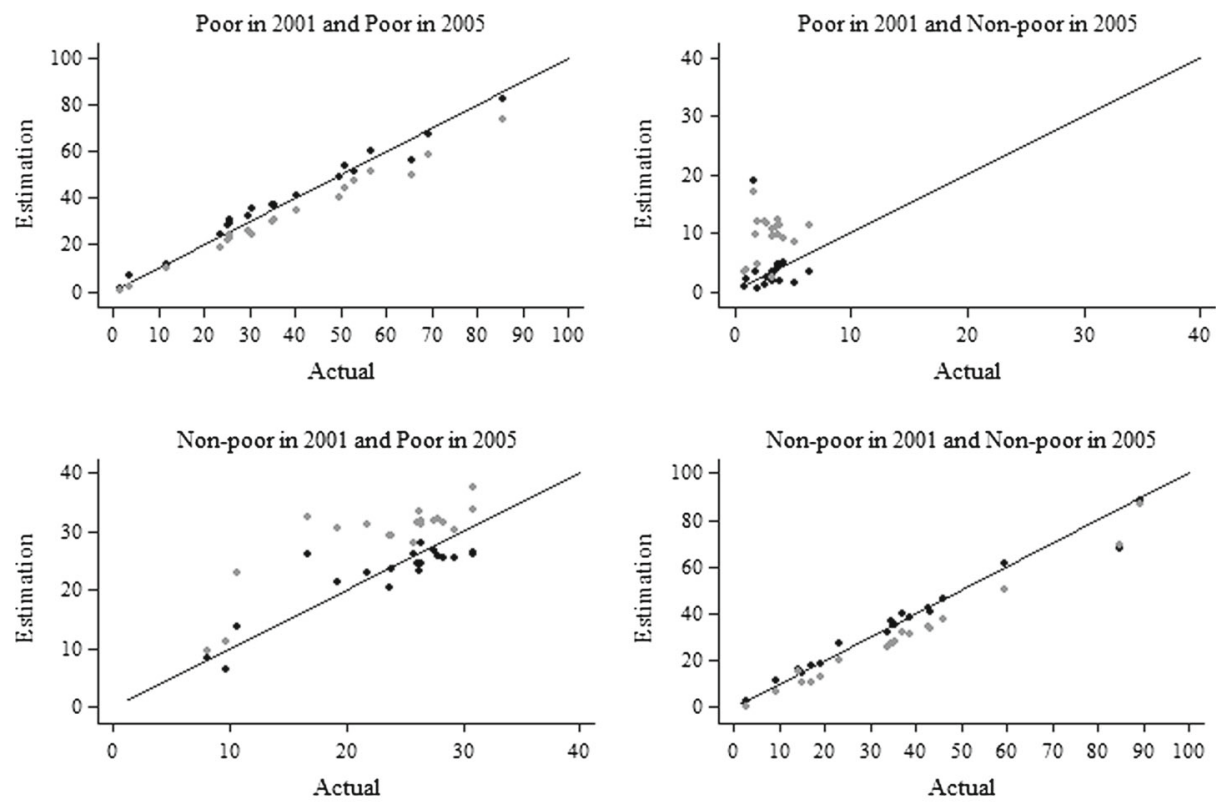

- Lower Bound

\section{- Upper Bound}

Fig. 2 Poverty dynamics - repeated cross sections vs. panel data by sub-population groups Nicaragua 20012005. Data source: EMNV, 2001-2005 Note: Results are constrained to the panel sample of households whose heads are between 25 and 65 years old. Results are weighted using household-level survey-sampling weights. The 45 degree line shows actual panel mobility. Upper bound estimations are based on 50 repetitions

the sub-groups even though upper bound estimates tend to overstate movements in and out of poverty (the off-diagonals), while the opposite happens to lower bound estimates. ${ }^{12}$

\section{Extensions}

\subsection{Choice of welfare measure: income vs. consumption}

Table 6 tests the robustness of results from using different welfare measure for the analysis. Specifically, we test whether using income instead of consumption as the dependent variable affects the estimates. Results are available only for Peru and Nicaragua due to data

\footnotetext{
${ }^{12}$ We conducted three sets of additional robustness checks that we do not report in detail for space considerations. First, we test whether the survey design and the sampling weights used affect the precision of the results. For this, in addition to the household sampling weights that are used in the main set of results, we redo the analysis using no weights in the first instance and using individual sampling weights in the second (as opposed to household weight used in the main text). We find that the technique performs well irrespective of survey design. Second, we conduct a robustness check for the upper bound estimates by using 150 and 300 repetitions instead of the 50 reported in the main text. Again, the results are similar suggesting that the precision gains beyond 50 replications are limited in our context. Finally, we reverse the forecasting direction and check whether poverty transitions estimates constructed using first round actual welfare levels and predicted welfare in the second round is equivalent to using actual second round welfare and predicted first round. Results suggest that the technique performs well irrespective of the forecasting direction.
} 
Table 6 Poverty dynamics from "pseudo" panel and actual panel data using income as the welfare measure

\begin{tabular}{llll}
\hline Status in Year[1], Year[2] & $\begin{array}{l}\text { Lower bound estimates } \\
{[1]}\end{array}$ & $\begin{array}{l}\text { Truth } \\
{[2]}\end{array}$ & $\begin{array}{l}\text { Upper bound estimates } \\
{[1]}\end{array}$ \\
\hline Panel A: Nicaragua & & & \\
Poor, Poor & 41.66 & $(32.57,39.77)$ & 29.02 \\
Poor, Non-poor & 7.80 & $(6.10,10.20)$ & 17.55 \\
Non-poor, Poor & 12.16 & $(14.78,20.50)$ & 24.80 \\
Non-poor, Non-poor & 38.38 & $(34.38,41.66)$ & 28.63 \\
& & & \\
Panel B: Peru & & & 16.99 \\
Poor, Poor & 29.13 & $(21.20,24.66)$ & 19.94 \\
Poor, Non-poor & 7.61 & $(12.21,15.03)$ & 14.63 \\
Non-poor, Poor & 2.49 & $(7.52,9.83)$ & 48.45 \\
Non-poor, Non-poor & 60.77 & $(52.71,56.80)$ & \\
& & & 684 \\
Observations Panel A & 684 & 684 & 2,279 \\
Observations Panel B & 2,279 & 2,279 & \\
\hline
\end{tabular}

Data source: Nicaragua EMNV 2001, and 2005; Peru Peruvian National Household Survey (ENAHO) 2008 and 2009.

R-squared is calculated for opposite halves of the total 2008 sample. Results are constrained to the panel sample of households whose heads are between 25 and 65 years old. Results are weighted using householdlevel survey-sampling weights. Results in columns [1] are based on a model with household time invariant characteristics, sub-national controls from census, and interactions between household time invariant characteristics and sub-national controls. Panel A shows results for Nicaragua, while panel B shows results for Peru. Results in column [2] show actual mobility. 95 percent confidence interval between parentheses. Upper bound estimations are based on 50 repetitions

availability. Results for Nicaragua are shown in panel A, while results for Peru are presented in panel B. The table shows that the method performs similarly irrespective of the welfare measure employed. Upper and lower bound estimates sandwich true poverty transitions confidence intervals as before. One notable difference is that the estimated bounds width is slightly larger in the case of income.

\subsection{Performance of short vs. long synthetic panels}

The three countries we study represent different spans of panel lengths: one year span in Peru, three, five and seven years span in Nicaragua, and five and ten years in Chile. This provides us an opportunity to test whether the actual time span of the estimated synthetic panels matters. Table 7 shows poverty transition estimates for the range of panel lengths we can calculate to test whether this affects the results. Panel A shows two equally spanned periods for Chile: from 1996 to 2001 in columns one through three and from 2001 to 2006 in columns four through six. Panel B shows two periods of different length for Nicaragua: from 1998 to 2001 in columns one through three and from 1998 to 2005 in columns four through six.

The results suggest that the technique performs similar irrespective of the panel length. In all the cases, the bounds overlap or fully encompass the actual panel poverty transition 
Table 7 Transition matrices - repeated cross sections vs. panel data using different panel length

\begin{tabular}{|c|c|c|c|c|c|c|}
\hline \multirow{2}{*}{$\begin{array}{c}\text { Status in Year[1], } \\
\text { Year[2] }\end{array}$} & \multicolumn{3}{|c|}{ Panel survey I } & \multicolumn{3}{|c|}{ Panel survey II } \\
\hline & $\begin{array}{l}\text { Lower } \\
\text { bound } \\
\text { estimates } \\
{[1]}\end{array}$ & $\begin{array}{l}\text { Truth } \\
\text { confidence } \\
\text { interval } \\
{[2]}\end{array}$ & $\begin{array}{l}\text { Upper } \\
\text { bound } \\
\text { estimates } \\
{[1]}\end{array}$ & $\begin{array}{l}\text { Lower } \\
\text { bound } \\
\text { estimates } \\
\text { [3] }\end{array}$ & $\begin{array}{l}\text { Truth } \\
\text { confidence } \\
\text { interval } \\
\text { [4] }\end{array}$ & $\begin{array}{l}\text { Upper } \\
\text { bound } \\
\text { estimates } \\
\text { [3] }\end{array}$ \\
\hline
\end{tabular}

Panel A: chile; years in panel survey I: 1996-2001; years in panel survey II: 2001-2006

$\begin{array}{lrcrrrr}\text { Poor, Poor } & 10.43 & (5.45,8.17) & 5.10 & 8.48 & (3.18,6.00) & 3.48 \\ \text { Poor, Non-poor } & 7.37 & (9.6,13.03) & 21.95 & 13.94 & (8.21,12.29) & 24.85 \\ \text { Non-poor, Poor } & 2.95 & (5.23,7.92) & 8.28 & 0.48 & (2.99,5.73) & 5.48 \\ \text { Non-poor, Non-poor } & 79.24 & (72.97,77.64) & 64.66 & 77.10 & (78.13,83.43) & 66.20\end{array}$

Panel B: Nicaragua; years in panel survey i: 1998-2001; years in panel survey II: 1998-2005

\begin{tabular}{lrccccr} 
Poor, Poor & 32.79 & $(24.44,31.27)$ & 21.08 & 28.16 & $(23.43,30.68)$ & 21.55 \\
Poor, Non-poor & 2.61 & $(4.95,8.81)$ & 14.35 & 1.20 & $(1.72,4.58)$ & 7.81 \\
Non-poor, Poor & 9.60 & $(11.84,17.21)$ & 21.31 & 31.32 & $(28.59,36.24)$ & 37.93 \\
Non-poor, Non-poor & 55.00 & $(46.91,54.53)$ & 43.27 & 39.33 & $(33.41,41.31)$ & 32.71 \\
Obs. Panel A & 1,312 & 1,312 & 1,312 & 851 & 851 & 851 \\
Obs. Panel B & 663 & 663 & 663 & 577 & 577 & 577 \\
\hline
\end{tabular}

Data source: Chile CASEN, 1996, 2001, and 2006; Nicaragua EMNV, 1998, 2001, and 2005.

R-squared is calculated for opposite halves of the total Year[1] sample. Results are constrained to the panel sample of households whose heads are between 25 and 65 years old. Results are weighted using householdlevel survey-sampling weights. Controls are the same as in columns [3] of Table 2c. Results in column [2] and [4] show actual panel mobility. 95 percent confidence interval between parentheses

estimates. For example, for Chile, the estimates for those remaining poor range from 5.10 and 10.43 percent between 1996 and 2001, while actual panel estimates for this group is 5.45 to 8.17 (given a 95 percent confidence interval due to the sampling error).

We also find that the bound width tends to become smaller for the longer panels. This is true for both countries we have available data to conduct this test. For example, for Nicaragua, the bounds estimates for those that remain poor is between 21.08 and 32.79 percent for the 1998 and 2001 period (the shorter panel span of three years for Nicaragua), or a bound width of 11.71 points. By contrast, the bounds for the longest panel span (seven years) we can construct are narrower: between 21.55 and 28.16 percent of households remain poor between 1998 and 2005 or a bound width of 6.61 percentage points and similar to that of the true panel estimates for the same period. These bounds are half the previous ones. We find similar patterns for Chile where we compare the results from a 5 year span to that of 10 years.

As mentioned earlier, panel data length rarely exceeds more than three years in developing country settings. These results therefore show that the method provides similar predictions of poverty transitions under various intervals between cross sections. The estimates seem to work slightly better for longer-term synthetic panels. 


\subsection{Extending beyond one threshold: transitions using two lines}

We finally test the performance of the approach if we introduce two threshold lines instead of one. This can be of particular interest to study transitions at different parts of the welfare distribution, such as movements from extreme poverty to moderate poverty; or from poverty to middle class. In this case, we estimate the joint distribution of transitions based on two threshold lines, giving rise to nine instead of four transitional estimates. In order to implement this, we conduct an ad hoc exercise exploring two thresholds: (i) official poverty line (using the same national poverty lines used in the previous set of exercises); and (ii) twice

Table 8 Transition matrices with two lines- repeated cross sections vs. panel data, moderate and twice the moderate poverty lines Peru 2008 and 2009

\begin{tabular}{|c|c|c|c|c|c|c|c|c|c|}
\hline \multirow[b]{2}{*}{ Status in 2008, 2009} & \multicolumn{4}{|c|}{ Lower bound estimates } & \multirow{2}{*}{$\begin{array}{l}\text { Truth } \\
{[5]}\end{array}$} & \multicolumn{4}{|c|}{ Upper bound estimates } \\
\hline & [1] & {$[2]$} & [3] & {$[4]$} & & {$[4]$} & {$[3]$} & {$[2]$} & [1] \\
\hline Poor, Poor & 33.54 & 30.81 & 28.88 & 28.83 & $\begin{array}{l}23.57 \\
(21.83,25.31)\end{array}$ & 18.28 & 17.24 & 17.21 & 15.87 \\
\hline Poor, Vulnerable & 2.19 & 4.29 & 5.54 & 4.82 & $\begin{array}{l}9.56 \\
(8.35,10.7)\end{array}$ & 11.94 & 12.22 & 12.69 & 14.16 \\
\hline Poor, Middle Class & 0.00 & 0.00 & 0.35 & 0.19 & $\begin{array}{l}0.40 \\
(0.142,0.66)\end{array}$ & 4.25 & 4.80 & 4.93 & 6.18 \\
\hline Vulnerable, Poor & 0.03 & 2.77 & 4.64 & 4.73 & $\begin{array}{l}9.31 \\
(8.11,10.5)\end{array}$ & 11.95 & 12.13 & 12.17 & 12.36 \\
\hline Vulnerable, Vulnerable & 38.20 & 33.60 & 30.07 & 31.62 & $\begin{array}{l}24.23 \\
(22.46,25.98)\end{array}$ & 18.56 & 17.88 & 17.65 & 16.02 \\
\hline Vulnerable, Middle Class & 2.79 & 4.59 & 5.59 & 4.95 & $\begin{array}{l}7.39 \\
(6.31,8.46)\end{array}$ & 9.91 & 10.33 & 10.68 & 10.23 \\
\hline Middle Class, Poor & 0.00 & 0.00 & 0.05 & 0.02 & $\begin{array}{l}0.69 \\
(0.35,1.03)\end{array}$ & 3.35 & 4.20 & 4.20 & 5.35 \\
\hline Middle Class, Vulnerable & 0.00 & 2.49 & 4.78 & 3.96 & $\begin{array}{l}6.60 \\
(5.58,7.62)\end{array}$ & 9.89 & 10.28 & 10.05 & 10.20 \\
\hline Middle Class, Middle Class & 23.25 & 21.45 & 20.09 & 20.90 & $\begin{array}{l}18.24 \\
(16.65,19.82)\end{array}$ & 11.87 & 10.91 & 10.43 & 9.62 \\
\hline R-squared & 0.41 & 0.53 & 0.57 & 0.62 & . & 0.62 & 0.57 & 0.53 & 0.41 \\
\hline Residual Correlation & 0.71 & 0.66 & 0.64 & 0.57 & . & 0.57 & 0.64 & 0.66 & 0.71 \\
\hline Observations & 2,279 & 2,279 & 2,279 & 2,279 & 2,279 & 2,279 & 2,279 & 2,279 & 2,279 \\
\hline
\end{tabular}

Data source: INEI - Peruvian National Household Survey (ENAHO), 2008-2009.

$\mathrm{R}$-squared is calculated for opposite halves of the total 2008 sample. Results are constrained to the panel sample of households whose heads are between 25 and 65 years old. Results are weighted using household-level survey-sampling weights. Columns [1] show a simple model with household time invariant characteristics. Columns [2] add sub-national controls from census and region of birth fixed-effects. Columns [3] add interactions between household time invariant characteristics and sub-national controls. Columns [4] add retrospective variables (asset ownership). Results in column [5] show actual panel mobility. 95 percent confidence interval between parentheses. Upper bound estimations are based on 50 repetitions. The poor are those living on less than the official poverty line, the vulnerable are those living between the official and twice the official poverty line, and the middle class are those living with more than twice the official poverty line 
the official poverty line. Table 8 presents these final set of results for Peru, while estimates for Chile and Nicaragua are available in the online appendix.

The majority of the true estimates lie within the estimated bounds (this is true across all three countries), even though this works better in the countries where the model fit is higher. Specifically, out of the 9 estimated transitions and bounds, the true estimate falls within the estimated bounds in 3 instances in Chile (lowest $R^{2}$ ), 7 in Nicaragua and all 9 in Peru (highest $\mathrm{R}^{2}$ ). Similarly, the 95 percent confidence interval of the actual estimate overlaps with all the estimated bounds.

As before, moving from the simplex to more complex specifications, estimated bounds are reduced considerably. Again, as with the main results, we also find that the specifications that include interaction terms (model 3) and retrospective variables (model 4 for Peru) perform the best in all three countries. For example, moving from the model with subnational characteristics (model 2) to the one with interactions (model 3) in Peru, the bounds' width for those that moved from being vulnerable to poor is reduced from 9.4 percentage points to 7.5 (row four, Table 8). These results are consistent with the earlier findings that indicate that model 3 should be preferred to the first 2 . And as before, we also find that when comparing the use of retrospective variables (model 4) with the one with interactions (model 3) for the case of Peru, we find a weak preference towards model 4. In general, these findings suggest that the extension to two lines works in the same way as the one with one line.

\section{Conclusion}

Recently, there has been growing interest among policy makers and researchers to study intra-generational mobility in and out of poverty. Panel datasets constitute the most appropriate information source for the study of mobility and poverty dynamics. Unfortunately, such surveys are rare and, where they exist, generally span only a few years and follow a relatively small number of households or individuals over time. To overcome this limitation, there is also a growing literature which studies intra-generational poverty transitions by means of cross-sectional surveys via the application of "pseudo-panel" methods. A new method proposed by [3], which largely relies on insights from poverty-mapping techniques [4], yields lower and upper bound estimates of poverty dynamics using cross sectional surveys. The significant advantage of this "synthetic panel" method is that it imposes fewer restrictions and structural assumptions than the earlier literature on pseudo-panels.

This paper uses three panel datasets for Chile, Nicaragua, and Peru to validate the methodology proposed by [3]. We first replicate the results in this different set of countries and context, and proceed to push further the validation by introducing a number of new sensitivity analyses and robustness checks. The methodology performs well in predicting the joint probabilities in and out of poverty by means of two rounds of cross-sectional data; true estimates lie within the two bounds most of the time. Specification of the underlying model of income/consumption matters for reducing the bounds, which can be narrowed considerably via the introduction of interaction terms and retrospective asset ownership as controls in the underlying model of consumption/income. Different choices of dependent and explanatory variables alter the results somewhat, giving rise to some insights about the potential use and data collection strategies. Finally, the method appears equally well-suited to the estimation of short-term but particularly long-term poverty transitions and can also accommodate more than one threshold. 
Acknowledgments We are grateful to Joao Pedro Wagner de Acevedo, Oscar Barriga Cabanillas, Monserrat Bustelo, Andres Castaneda, Hai-Anh Dang, Amer Hasan, participants at the Institut d'Analisi Economica/World Bank workshop on "Socio-Economic Mobility and the Middle Class in Latin America," LACEA 2012, as well as participants at the World Bank "Summer Initiative on Research on Poverty Inequality and Gender" whose suggestions greatly improved earlier drafts of the paper. We are also grateful to two anonymous referees. All remaining errors are ours. The views expressed here are those of the authors and should not be attributed to World Bank or its affiliates.

\section{References}

1. Bourguignon, F., Goh, C., Kim, D.: Estimating individual vulnerability to poverty with pseudo-panel data. World Bank Policy Research Working Paper No. 3375 (2004)

2. Bourguignon, F., Chor-ching, G., DaeIl, K.: Estimating individual vulnerability to poverty with pseudopanel data. World Bank Policy Research Working Paper No. 3375 (2004)

3. Dang, H.-A., Lanjouw, P., Luoto, J., McKenzie, D.: Using repeated cross-sections to explore movements into and out of poverty. J. Dev. Econ. Elsevier 107(C), 112-128 (2014)

4. Elbers, C., Lanjouw, J.O., Lanjouw, P.: Micro-level estimation of poverty and inequality. Econometrica 71(1), 355-364 (2003) 